\title{
A Transition in Brain State during Propofol-Induced Unconsciousness
}

\author{
Eran A. Mukamel, ${ }^{1,2}$ Elvira Pirondini, ${ }^{3}$ Behtash Babadi, ${ }^{3}$ Kin Foon Kevin Wong, ${ }^{3}$ Eric T. Pierce, ${ }^{3}$ P. Grace Harrell, ${ }^{3}$ \\ John L. Walsh, ${ }^{3}$ Andres F. Salazar-Gomez, ${ }^{3}$ Sydney S. Cash,${ }^{4}$ Emad N. Eskandar, ${ }^{5}$ Veronica S. Weiner, ${ }^{6}$ \\ Emery N. Brown, ${ }^{3,7,8,9}$ and Patrick L. Purdon 3,7 \\ ${ }^{1}$ Swartz Program for Theoretical Neuroscience, Harvard University, Cambridge, Massachusetts 02138 , ${ }^{2}$ Center for Theoretical Biological Physics, University \\ of California, San Diego, La Jolla, California 92093 and Computational Neurobiology Laboratory, Salk Institute for Biological Studies, San Diego, California \\ 92037, ${ }^{3}$ Department of Anesthesia, Critical Care and Pain Medicine, Massachusetts General Hospital, Boston, Massachusetts 02114, ${ }^{4}$ Department of \\ Neurology, Massachusetts General Hospital, Boston, Massachusetts 02114, 5epartment of Neurosurgery, Massachusetts General Hospital, Boston, \\ Massachusetts 02114, ${ }^{6}$ Department of Brain and Cognitive Science, Massachusetts Institute of Technology, Cambridge, Massachusetts 02139, ${ }^{7}$ Harvard \\ Medical School, Boston, Massachusetts 02115, ${ }^{8}$ Division of Health Science and Technology, Harvard-Massachusetts Institute of Technology, Cambridge, \\ Massachusetts 02139, and ' Institute for Medical Engineering and Sciences, Massachusetts Institute of Technology, Cambridge, Massachusetts 02139
}

Rhythmic oscillations shape cortical dynamics during active behavior, sleep, and general anesthesia. Cross-frequency phase-amplitude coupling is a prominent feature of cortical oscillations, but its role in organizing conscious and unconscious brain states is poorly understood. Using high-density EEG and intracranial electrocorticography during gradual induction of propofol general anesthesia in humans, we discovered a rapid drug-induced transition between distinct states with opposite phase-amplitude coupling and different cortical source distributions. One state occurs during unconsciousness and may be similar to sleep slow oscillations. A second state occurs at the loss or recovery of consciousness and resembles an enhanced slow cortical potential. These results provide objective electrophysiological landmarks of distinct unconscious brain states, and could be used to help improve EEG-based monitoring for general anesthesia.

Key words: $\alpha$ rhythm; anesthesia; cross-frequency coupling; propofol; Slow oscillation; unconsciousness

\section{Introduction}

Although the molecular actions of many anesthetic drugs at specific receptors are known (Brown et al., 2010), alterations in network dynamics that disrupt information processing and produce unconsciousness have remained elusive (Alkire et al., 2008). Loss of consciousness is accompanied by increased EEG power across a broad range of frequencies $<40 \mathrm{~Hz}$ (Gugino et al., 2001; Feshchenko et al., 2004; Murphy et al., 2011; Purdon et al., 2013). Traditional analyses, including visual interpretation of EEG traces and time-frequency power spectral analysis, are computationally simple and play a central role in neurophysiology and clinical EEG applications. However, power spectral analysis treats the EEG as a collection of independent frequency bands, offering

\footnotetext{
Received Dec. 19, 2012; revised Nov. 5, 2013; accepted Nov. 10, 2013.

Author contributions: E.A.M., E.N.B., and P.L.P. designed research; E.A.M., E.P., B.B., K.F.K.W., E.T.P., P.G.H., J.L.W., A.F.S.-G., S.S.C., E.N.E., V.S.W., E.N.B., and P.L.P. performed research; E.A.M., E.P., B.B., and K.F.K.W. analyzed data; E.A.M. and P.L.P. wrote the paper.

This work was supported by a Swartz Fellowship in Theoretical Neuroscience (E.A.M.), the University of California-San Diego (enter for Biological Physics (E.A.M.), and National Institutes of Health Grants K99NS080911 (E.A.M.), DP2-0D006454 (P.L.P.), K25-NS057580 (P.L.P.), DP1-0D003646-01 (E.N.B.), R01-EB006385 (E.N.B., P.L.P.), and R01-MH071847 (E.N.B.).

The authors declare no competing financial interests.

Correspondence should be addressed to Dr. Patrick L. Purdon, Department of Anesthesia, Critical Care, and Pain Medicine, Building 149, Thirteenth Street, Room 4012, Charlestown, MA 02129-2060. E-mail: patrickp@nmr.mgh.harvard.edu.

DOI:10.1523/JNEUROSCI.5813-12.2014

Copyright $\odot 2014$ the authors $\quad 0270-6474 / 14 / 330839-07 \$ 15.00 / 0$
}

limited insight into the modulation of network activity as a whole. Because cortical networks frequently express oscillations in multiple frequency bands simultaneously, nonlinear biophysical processes, such as neuronal spiking, induce cross-frequency coupling, which is undetectable by spectral analysis (Roopun et al., 2008). Identifying global brain states, such as sleep stages or general anesthesia-induced unconsciousness, remains a significant challenge for understanding cortical dynamics (Gervasoni et al., 2004). Moreover, an EEG-based framework for understanding brain state transitions during general anesthesia will be critical for improving patient monitoring to avoid complications, such as intraoperative awareness (Avidan et al., 2011).

We reasoned that critical information for identifying and characterizing distinct global brain states may be contained in patterns of coupling between distinct frequency bands. A simple form of cross-frequency interaction is phase-amplitude coupling, in which power within one frequency band waxes and wanes at specific phases of an underlying, lower-frequency rhythm (Jensen and Colgin, 2007). Phase-amplitude coupling is widespread during sleep, waking (He et al., 2010), and general anesthesia (Molaee-Ardekani et al., 2007; Breshears et al., 2010; Mukamel et al., 2011; Purdon et al., 2013) and has been related to attention and behavior in human and primate cortex (Canolty et al., 2006; Lakatos et al., 2008). In previous work, we discovered two forms of coupling between the phase of low-frequency activity (LFA, $0.1-2 \mathrm{~Hz}$ ) and the amplitude of $\alpha$ rhythms $(8-14 \mathrm{~Hz})$ in 
scalp EEG recordings during propofol general anesthesia (Mukamel et al., 2011; Purdon et al., 2013). One form of coupling occurred during the transitions to and from the unconscious state ("troughmax"), whereas the other occurred at deep levels of unconsciousness ("peak-max") (Mukamel et al., 2011; Purdon et al., 2013). The cortical networks involved in these distinct modulation patterns, their frequency dependence, and their relationship to other brain states, such as burst suppression, are unclear. Here we investigate the cortical generators of these modulation patterns using source localization analysis and intracranial electrocorticography, analyze their frequency dependence, demonstrate these effects in individual subjects, and clarify their relationship to burst suppression. We find that these patterns of cross-frequency coupling reflect dynamics within distinct cortical networks and identify a transition in global brain state.

\section{Materials and Methods}

Subjects and recordings. Following approval from the Massachusetts General Hospital Human Research Committee, we induced and allowed recovery from general anesthesia in 10 healthy volunteers ( 5 male) using the intravenous anesthetic propofol (2,6 di-isopropylphenol). Propofol concentration increased in steps from 0 to $5 \mu \mathrm{g} / \mathrm{ml}$ every $14 \mathrm{~min}$, followed by gradual reduction (see Fig. 1a). We recorded 64 channel EEG using a BrainVision MRI Plus system (BrainAmp MRPlus, BrainProducts) with sampling rate $5 \mathrm{kHz}$, resolution $0.5 \mu \mathrm{V}$ least significant bit, and bandwidth $0.016-1000 \mathrm{~Hz}$. We also recorded galvanic skin response and plethysmography (PowerLab; AD Instruments). Electrodes, amplifiers, and filter settings provided accurate and unbiased recording of the entire frequency range analyzed in this study $(0.1-50 \mathrm{~Hz})$. A Bayesian method was used to estimate the timevarying probability of response (see Fig. 1b) (Smith et al., 2009). We defined the time of loss of consciousness (LOC), $t_{L O C}$, and return of consciousness (ROC), $t_{R O C}$, as the first and last times at which the median response probability was $<0.05$.

EEG data were rereferenced using a Laplacian montage by subtracting the mean of each channel's nearest neighbors (Nunez and Pilgreen, 1991). The Laplacian montage improves spatial localization of focal sources but attenuates EEG components with low spatial frequencies. Because these components tend to have low temporal frequencies, it is also found to attenuate low temporal frequencies. We verified that the reference choice had a minor impact on our measurement of phaseamplitude coupling by repeating the analysis using the average of mastoid electrodes as a reference. Raw signals, $x(t)$, were first smoothed using an anti-aliasing filter and downsampled to $250 \mathrm{~Hz}$. We removed ultralow-frequency drift by subtracting a piecewise quadratic spline fit to the signal with knots every $15 \mathrm{~s}$. We rejected bad channels by visual inspection. We adopted a conservative procedure to remove low-frequency, large-amplitude EEG artifacts caused by movements while subjects were awake. We extracted the low-frequency signal, $x_{l o}(t)$, by applying a bandpass filter $(0.2-6 \mathrm{~Hz})$ and downsampling to $5 \mathrm{~Hz}$, then applying a median filter (window size $30 \mathrm{~s}$ ) to $\left|x_{l o}(t)\right|$. We defined artifacts as any time point for which $\left|x_{l o}(t)\right|$ was at least 10 -fold greater than this local threshold. We excluded data within $\pm 5 \mathrm{~s}$ of any artifact on each channel. Power spectral density (see Fig. 1c) was computed using a multitaper method (window size: 2 s, 3 tapers) (Mitra and Bokil, 2008).

Phase-amplitude coupling analysis. We constructed a phase-amplitude modulogram, $M(t, \phi)$, characterizing the relative amplitude of activity in a frequency band $f_{a m p}$, as a function of the phase of the rhythm in band $f_{p h}$. We bandpass filtered the EEG signal, $x(t)$, to extract each frequency band of interest, $x_{b}(t), b \in\{a m p, p h\}$, Filters were chosen to adequately isolate these frequency bands while allowing temporal resolution of changes in phase-amplitude coupling, which occur within $<2 \mathrm{~min}$. We used symmetric finite impulse response filters designed using a least-squares approach (MATLAB function firls; $f_{p h}$ passband $=0.1-1 \mathrm{~Hz}$, transition bands $=0.085-0.1$ and $1-1.15 \mathrm{~Hz}$, attenutation in stop band $\geq 17 \mathrm{~dB}$, filter order $2207 ; f_{\text {amp}}$, passband $=8-13.9 \mathrm{~Hz}$, transition bands $=5.9-8.0$ and $13.9-16.0 \mathrm{~Hz}$, attenutation in stop band $\geq 60 \mathrm{~dB}$, filter order 513). To ensure that our findings were unaffected by artifacts of filtering, we assessed statistical significance using a permutation procedure with the same filter settings (below). Next, we used a Hilbert transform to extract the instantaneous amplitude and phase.

We computed the modulogram by assigning each temporal sample to one of $N=18$ equally spaced phase bins based on the instantaneous value of $\psi_{p h}(t)$, then averaging the corresponding values of $A_{a m p}(t)$ within a 2 min epoch as follows:

$$
M(t, \phi)=\frac{\int \begin{array}{c}
t+\frac{\delta t}{2} \\
t-\frac{\delta t}{2}
\end{array} \int_{\phi-\frac{\delta \phi}{2}}^{\phi+\frac{\delta \phi}{2}} A_{a m p}\left(t^{\prime}\right) \delta\left(\psi_{p h}\left(t^{\prime}\right)-\phi^{\prime}\right) d \phi^{\prime} d t^{\prime}}{\int_{t-\frac{\delta t}{2}}^{t+\frac{\delta t}{2}} A_{a m p}\left(t^{\prime}\right) d t^{\prime}}
$$



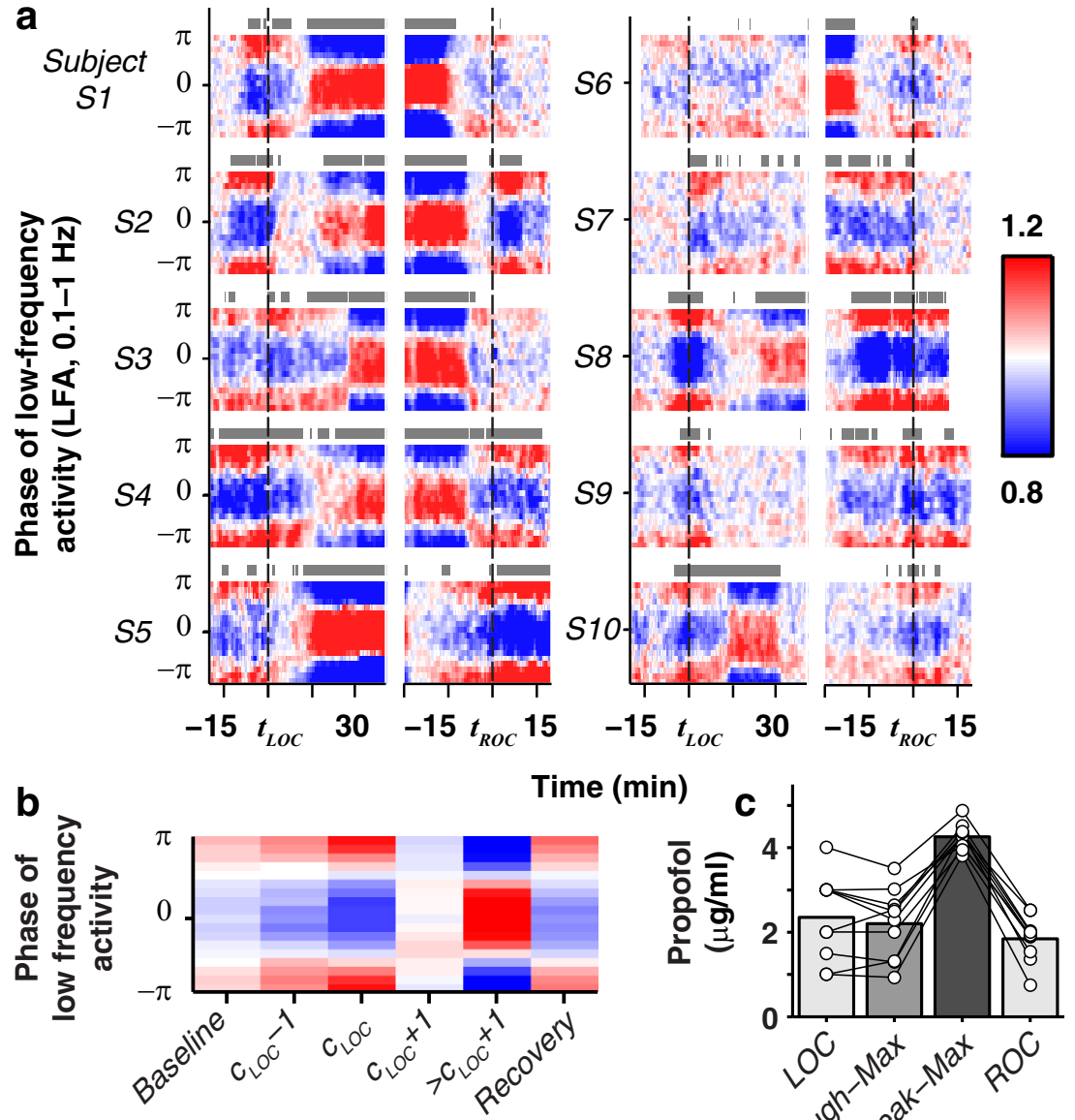

Propofol effect-site concentration $(\mu \mathrm{g} / \mathrm{ml})$
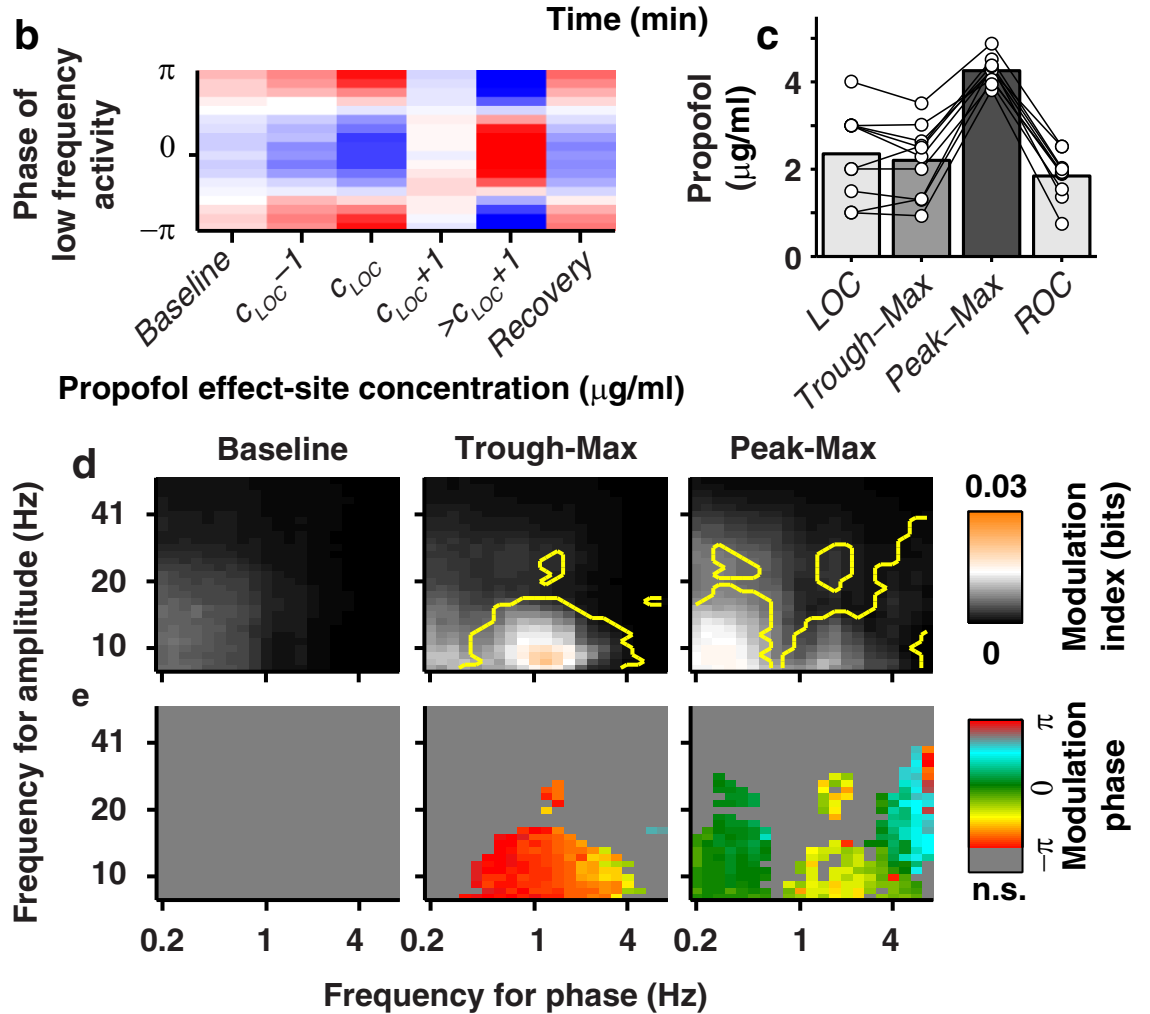

Figure 2. Stereotyped phase-amplitude coupling in unconsciousness. $\boldsymbol{a}$, Frontal phase-amplitude coupling aligned to $t_{L O C}$ and $t_{R O C}$ (gray bars: $p<0.005$, uncorrected). $\boldsymbol{b}$, Mean coupling pattern across subjects at each drug concentration. $\boldsymbol{c}$, Mean propofol concentration at $\mathrm{LOC}, \mathrm{ROC}$, and during trough-max and peak-max epochs (circles represent individual subjects). $\boldsymbol{d}, \boldsymbol{e}$, Median $\mathrm{MI}$ (d) and modulation phase $(\boldsymbol{e})$ across subjects as a function of the center of the frequency bands used for phase and amplitude. Yellow contour indicates that $\geq 6$ of 10 subjects showed significant modulation ( $p<0.05$; n.s., not significant).

where $\delta t=120 s$ and $\delta \phi=\frac{2 \pi}{N}$. Note that $\sum_{n=1}^{N} M\left(t, \phi_{n}\right)=1, \phi_{n}$ $=2 \pi n / N$, so that $M(t, \phi)$ is a normalized distribution over phase bins. To reduce noise in estimated modulograms (see Figs. $1 d, 2 a$, and $3 c$ ), we averaged the value of $M(t, \phi)$ from six frontal electrodes near $\mathrm{Fz}$ in the standard montage (see Fig. 4, asterisk).

The modulation index, $M I(t)$ in bits, was defined (Tort et al., 2010) as follows:

$$
M I(t)=\sum_{n=1}^{N} M\left(t, \phi_{n}\right) \log _{2} \frac{M\left(t, \phi_{n}\right)}{1 / N}
$$

We assessed statistical significance by a permutation test. We sampled 200 random time shifts, $\Delta t$, from a uniform distribution on the interval $[-60,60 \mathrm{~s}]$. We then computed $M I_{\text {perm }}(t)$ using the original phase, $\psi_{p h}(t)$, and the shifted amplitude, $A_{a m p}(t-\Delta t)$. MI $(t)$ was judged significant if it exceeded $95 \%$ of the permuted values, $M I_{\text {perm }}(t)$.

In case of significant coupling, we determined the phase of $f_{p h}$ at which the $f_{a m p}$ amplitude is greatest by finding the phase of the sinusoid that best fit the modulogram at each time point as follows:

$$
\Phi(t) \equiv \arg \left[\sum_{n=1}^{N} e^{i \phi_{n}} M\left(t, \phi_{n}\right)\right] .
$$

In recordings from individual subjects, we observed two forms of modulation: peak-max and trough-max. In the peak-max pattern, $\alpha$ amplitude is greatest at the surface-positive phase of the LFA; the reverse relationship occurred during trough-max coupling (see Fig. 1). We defined baseline (before propofol onset), trough-max, and peak-max epochs for each subject to analyze the spatial and frequency-dependent properties during each state (see Figs. $2 c-e$ and $4 a-c$ ). During the unconscious period, from LOC to ROC, we tested each $2 \mathrm{~min}$ window for significant phase-amplitude coupling. A window was significant if the average modulation index (MI) across six frontal electrodes exceeded the average of the 95th percentile of the shuffled MI at the same set of electrodes. For each unconscious epoch with significant coupling, we defined the epoch as trough-maxif $|\Phi(t)-\pi|<\frac{\pi}{4}$, and peak-max if $|\Phi(t)|<\frac{\pi}{4}$.

Spatial analysis. To analyze the scalp topography of phase-amplitude coupling and EEG power (see Fig. $4 a, b$ ), we generated scalp maps using subjects' individually measured electrode locations. We combined the interpolated maps across subjects by taking the median.

To estimate the spatial distribution of cortical currents responsible for peak- and troughmax EEG coupling, we performed source localization analysis of the EEG signal using the minimum norm estimate (MNE) (Hämäläinen et al., 1993) followed by phase-amplitude coupling analysis of the estimated cortical current sources. Freesurfer (Dale et al., 1999) was used to reconstruct tissue surfaces for the forward model based on high-resolution structural MRI obtained for each subject (T1 MPRAGE, $1.3 \mathrm{~mm}$ slice thickness, $1.3 \times 1 \mathrm{~mm}$ in-plane resolution, TR/TE $=2530 / 3.3 \mathrm{~ms}, 7^{\circ}$ flip angle; Siemens Trio 3 Tesla MR scanner). A three layer boundary element forward model was constructed using MNE software (Hämäläinen et al., 1993). One subject was excluded from localization analysis because the number of bad channels prevented accurate source estimation. Localization analysis used a reduced-dimension source space of 1284 patches of 
a

\section{no burst-suppression}

i. Peak-Max

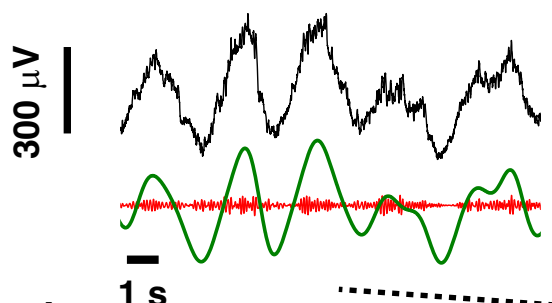

b $1 \mathrm{~s}$

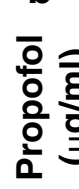

응 ${ }^{5}$ 打

$c$

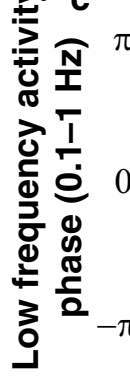

.
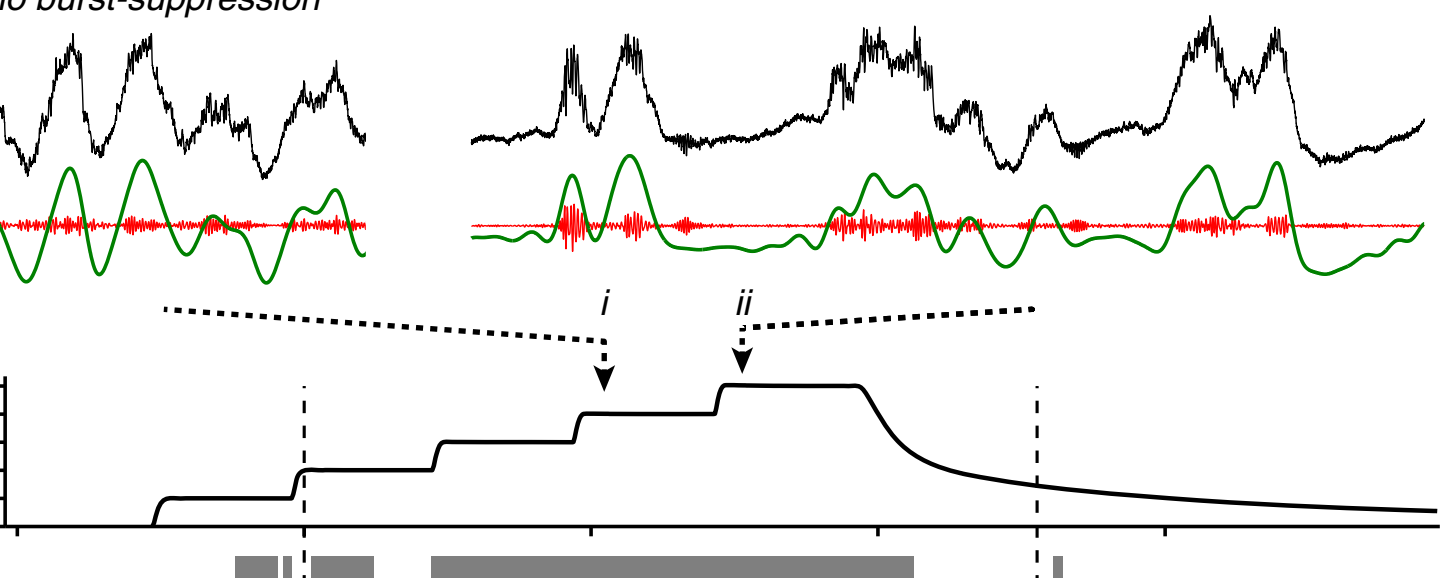

ii. Peak-Max
burst-suppresion 

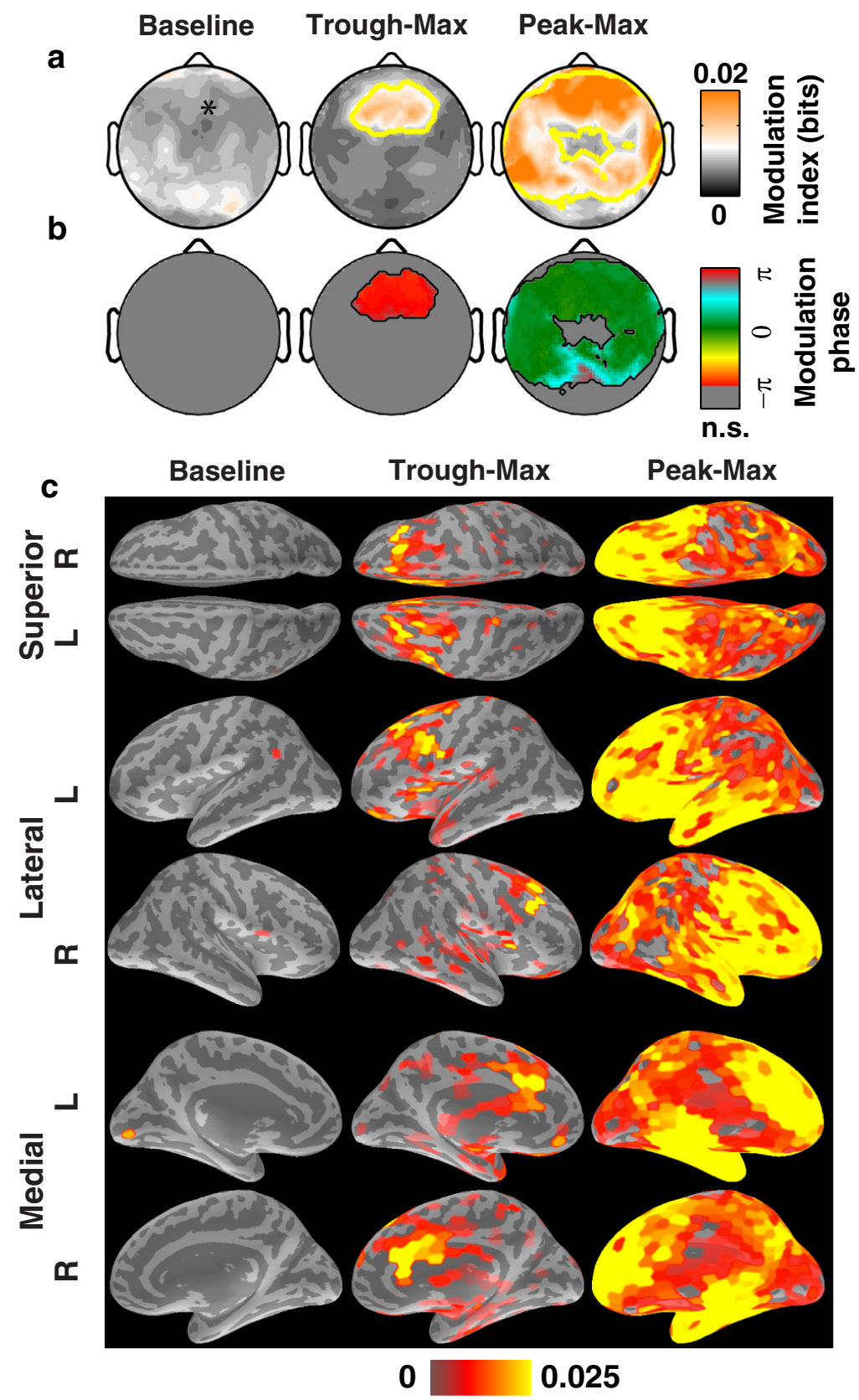

Modulation index (bits)

d Baseline

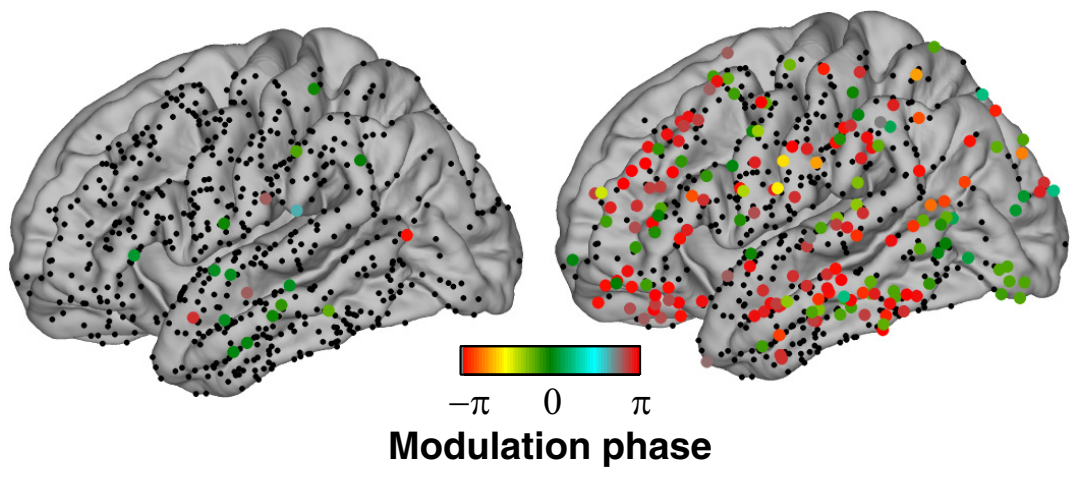

Figure 4. Spatial distribution of phase-amplitude coupling. $\boldsymbol{a}, \boldsymbol{b}$, Scalp distribution of $\mathrm{MI}(\boldsymbol{a})$ and phase (b) (median across 10 subjects). *Location of frontal electrodes used in Figs. 1, 2, and 3. $\boldsymbol{a}$, Yellow contour indicates locations where at least 6 of 10
Overall, coupling was significant at frontal locations during $67 \%$ of unconscious epochs; only $11 \%$ were significant before propofol administration. The median MI, a measure of coupling strength (Materials and Methods), doubled from $6 \times 10^{-3}$ bits at baseline to $12 \times 10^{-3}$ bits after LOC ( $p<10^{-3}$, Mann-Whitney $U$ test).

We next examined the frequency dependence of phase-amplitude coupling. Although significant phase-amplitude coupling was observed in some subjects while they were awake before LOC (Fig. 1a) (He et al., 2010), overall coupling before propofol administration was not consistent across subjects for any of the frequencies we tested $(0.2-50 \mathrm{~Hz}$; Fig. $2 d, e)$. After LOC, phase-amplitude coupling was concentrated within the LFA and $\alpha$ bands. Trough-max coupling linked LFA and $\delta$ phase $(0.4-4 \mathrm{~Hz})$ with $\alpha$ and low $\beta$ amplitude (8.3-17 Hz). During peak-max epochs, we found separate patterns of coupling between $\alpha$ amplitude and the LFA $(0.1-1 \mathrm{~Hz})$ and $\delta(1-4 \mathrm{~Hz})$ bands. $\alpha$ amplitude was highest at the peaks of the LFA (Fig. 2e, green), whereas coupling to the $\delta$ band peaked $\sim-\pi / 2$ (Fig. 2e, yellow)

Profound unconsciousness during general anesthesia, coma, and hypothermia can evoke a burst suppression pattern in which high-frequency activity alternates with isoelectric periods (Steriade et al., 1994; Brown et al., 2010). Burst suppression is a distinct state from sleep slow waves and slow oscillations during general anesthesia, which are more regular and alternate at a faster rate (Ching et al., 2012). In our study, 4 of 10 subjects entered a state of burst suppression at the highest propofol concentration. These subjects exhibited peak-max coupling during both burst suppression and nonburst suppression epochs (Fig. 3). Peak-max coupling is therefore not simply a consequence of burst suppression but instead represents a network state, which can occur at lower anesthetic drug doses.

Peak- and trough-max coupling had distinct spatial profiles over the scalp and across cortical regions. Traditional

subjects had significant modulation ( $p<0.05$; n.s., not significant). c, Average Ml at cortical patches estimated by source localization analysis of the EEG. Only patches with significant modulation are included ( $1 \%$ false discovery rate). $\boldsymbol{d}$, Locations of intracranial cortical surface electrodes $(n=605$ sites, 8 patients), mapped to an average cortical surface. Colored points indicate modulation phase of electrodes with significant phase-amplitude coupling. 
frequency-band analysis has identified the occipital-to-frontal shift in low-frequency $(<40 \mathrm{~Hz})$ scalp EEG power as a hallmark of general anesthesia (Gugino et al., 2001; Cimenser et al., 2011; Purdon et al., 2013). During the transition to unconsciousness, we found that trough-max coupling of $\alpha$ amplitude with LFA phase was likewise concentrated at frontal electrodes (Fig. $4 a, b$ ). However, peak-max coupling dominated activity throughout frontal, temporal, and posterocentral regions. We used each subject's anatomical MRI to reconstruct cranial tissue surfaces and perform biophysical model-based source localization using a minimum norm estimation algorithm (Hämäläinen et al., 1993) (Fig. 4c). This procedure is biased toward distributed cortical sources, so our results represent a conservative estimate of localization. We found significant trough-max coupling in anterior cingulate and frontal cortices bilaterally, whereas peak-max coupling extended throughout much of the cortex and was strongest in frontal and temporal lobes.

To directly examine the cortical sources of phase-amplitude coupled activity with high spatial resolution, we recorded intracranial ECoG using subdural electrode grids in 8 epilepsy patients during induction of general anesthesia with propofol (605 total electrodes). After LOC, significant coupling appeared in frontal, occipital, and temporal cortices (Fig. $4 d$ ). The sign of the referential ECoG varies depending on the geometry of local sources, resulting in a bimodal distribution of coupling phase concentrated at 0 and $\pi$ (Fig. $4 d$, green and red, respectively).

\section{Discussion}

Our data show that propofol consistently evokes two distinct cortical states with opposite phase-amplitude coupling. These EEG patterns appear in a stereotyped progression during the induction of and recovery from unconsciousness. In contrast with phase-amplitude coupling observed during waking and sleep states (He et al., 2010), the patterns we observed critically involve the frontal $\alpha$ rhythm, which is a hallmark of general anesthesia (Feshchenko et al., 2004; Breshears et al., 2010; Brown et al., 2010; Purdon et al., 2013). Peak-max coupling resembles the wellstudied slow oscillation (Steriade et al., 1993), in which scalppositive waves are associated with transient activated cortical UP/ON states showing increased broadband EEG, local field potential power, and multiunit activity, whereas scalp-negative waves are associated with quiescent DOWN/OFF states (Nir et al., 2011; Lewis et al., 2012). We found that peak-max coupling does not require a burst suppression activity pattern. Rather, peak-max coupling may be a general signature of unconsciousness in the cortex that precedes the onset of burst suppression.

The trough-max pattern parallels reports of increased cortical excitability and attention during the surface-negative phase of slow cortical potentials (Vanhatalo et al., 2004; He and Raichle, 2009). This pattern is localized in anterior cingulate and frontal cortices, the most rostral portion of an ascending arousal system, including brainstem, thalamic, and cortical networks that becomes more metabolically active during emergence from propofol-induced unconsciousness (Långsjö et al., 2012). Activity in anterior cingulate and frontal cortices also covaries with spontaneous fluctuations in internal awareness (Vanhaudenhuyse et al., 2011); the trough-max pattern might therefore be associated with propofol-induced changes in circuits mediating internal awareness.

The transition we have identified in cortical dynamics shows that unconsciousness during propofol general anesthesia is not a unitary brain state (Alkire et al., 2008). Instead, propofol evokes at least two distinct states with opposite patterns of crossfrequency phase-amplitude coupling that engage different corti- cal networks. The fact that these opposing modulation patterns are mutually exclusive, with distinct spatial distributions, suggests that alternation between widespread cortical $\mathrm{ON}$ and OFF states during peak-max coupling begins only after disruption of the frontal trough-max pattern. These objective EEG landmarks enable reliable interpretation of the physiology and functional significance of cortical activity during unconsciousness.

\section{References}

Alkire MT, Hudetz AG, Tononi G (2008) Consciousness and anesthesia. Science 322:876-880. CrossRef Medline

Avidan MS, Jacobsohn E, Glick D, Burnside BA, Zhang L, Villafranca A, Karl L, Kamal S, Torres B, O’Connor M, Evers AS, Gradwohl S, Lin N, Palanca BJ, Mashour GA (2011) Prevention of intraoperative awareness in a high-risk surgical population. N Engl J Med 365:591-600. CrossRef Medline

Benjamini Y, Yekutieli D (2001) The control of the false discovery rate in multiple testing under dependency. Ann Stat 29:1165-1188. CrossRef

Breshears JD, Roland JL, Sharma M, Gaona CM, Freudenburg ZV, Tempelhoff R, Avidan MS, Leuthardt EC (2010) Stable and dynamic cortical electrophysiology of induction and emergence with propofol anesthesia. Proc Natl Acad Sci U S A 107:21170-21175. CrossRef Medline

Brown EN, Lydic R, Schiff ND (2010) General anesthesia, sleep, and coma. N Engl J Med 363:2638-2650. CrossRef Medline

Canolty RT, Edwards E, Dalal SS, Soltani M, Nagarajan SS, Kirsch HE, Berger MS, Barbaro NM, Knight RT (2006) High $\gamma$ power is phase-locked to $\theta$ oscillations in human neocortex. Science 313:1626-1628. CrossRef Medline

Ching S, Purdon PL, Vijayan S, Kopell NJ, Brown EN (2012) A neurophysiological-metabolic model for burst suppression. Proc Natl Acad Sci U S A 109:3095-3100. CrossRef Medline

Cimenser A, Purdon PL, Pierce ET, Walsh JL, Salazar-Gomez AF, Harrell PG, Tavares-Stoeckel C, Habeeb K, Brown EN (2011) Tracking brain states under general anesthesia by using global coherence analysis. Proc Natl Acad Sci U S A 108:8832-8837. CrossRef Medline

Dale AM, Fischl B, Sereno MI (1999) Cortical surface-based analysis: I. Segmentation and surface reconstruction. Neuroimage 9:179-194. CrossRef Medline

Dykstra AR, Chan AM, Quinn BT, Zepeda R, Keller CJ, Cormier J, Madsen JR, Eskandar EN, Cash SS (2012) Individualized localization and cortical surface-based registration of intracranial electrodes. Neuroimage 59: 3563-3570. CrossRef Medline

Feshchenko VA, Veselis RA, Reinsel RA (2004) Propofol-induced alpha rhythm. Neuropsychobiology 50:257-266. Medline

Fischl B, Sereno MI, Tootell RB, Dale AM (1999) High-resolution intersubject averaging and a coordinate system for the cortical surface. Hum Brain Mapp 8:272-284. CrossRef Medline

Gervasoni D, Lin SC, Ribeiro S, Soares ES, Pantoja J, Nicolelis MA (2004) Global forebrain dynamics predict rat behavioral states and their transitions. J Neurosci 24:11137-11147. CrossRef Medline

Gugino LD, Chabot RJ, Prichep LS, John ER, Formanek V, Aglio LS (2001) Quantitative EEG changes associated with loss and return of consciousness in healthy adult volunteers anaesthetized with propofol or sevoflurane. Br J Anaesth 87:421-428. CrossRef Medline

Hämäläinen M, Hari R, Ilmoniemi RJ, Knuutila J, Lounasmaa OV (1993) Magnetoencephalography: theory, instrumentation, and applications to noninvasive studies of the working human brain. Rev Mod Phys 65:413497. CrossRef

He BJ, Raichle ME (2009) The fMRI signal, slow cortical potential and consciousness. Trends Cogn Sci 13:302-309. CrossRef Medline

He BJ, Zempel JM, Snyder AZ, Raichle ME (2010) The temporal structures and functional significance of scale-free brain activity. Neuron 66:353369. CrossRef Medline

Jensen O, Colgin LL (2007) Cross-frequency coupling between neuronal oscillations. Trends Cogn Sci 11:267-269. CrossRef Medline

Lakatos P, Karmos G, Mehta AD, Ulbert I, Schroeder CE (2008) Entrainment of neuronal oscillations as a mechanism of attentional selection. Science 320:110-113. CrossRef Medline

Långsjö JW, Alkire MT, Kaskinoro K, Hayama H, Maksimow A, Kaisti KK, Aalto S, Aantaa R, Jääskeläinen SK, Revonsuo A, Scheinin H (2012) Re- 
turning from oblivion: imaging the neural core of consciousness. J Neurosci 32:4935-4943. CrossRef Medline

Lewis LD, Weiner VS, Mukamel EA, Donoghue JA, Eskandar EN, Madsen JR, Anderson WS, Hochberg LR, Cash SS, Brown EN, Purdon PL (2012) Rapid fragmentation of neuronal networks at the onset of propofolinduced unconsciousness. Proc Natl Acad Sci U S A 109:E3377-E3386. CrossRef Medline

Limpiti T, Van Veen BD, Wakai RT (2006) Cortical patch basis model for spatially extended neural activity. IEEE Trans Biomed Eng 53:1740-1754. CrossRef Medline

Mitra P, Bokil H (2008) Observed brain dynamics. Oxford: Oxford UP.

Molaee-Ardekani B, Senhadji L, Shamsollahi MB, Wodey E, VosoughiVahdat B (2007) Delta waves differently modulate high frequency components of EEG oscillations in various unconsciousness levels. Conf Proc IEEE Eng Med Biol Soc 2007:1294-1297. Medline

Mukamel EA, Wong KF, Prerau MJ, Brown EN, Purdon PL (2011) Phasebased measures of cross-frequency coupling in brain electrical dynamics under general anesthesia. Conf Proc IEEE Eng Med Biol Soc 2011:19811984. CrossRef Medline

Murphy M, Bruno MA, Riedner BA, Boveroux P, Noirhomme Q, Landsness EC, Brichant JF, Phillips C, Massimini M, Laureys S, Tononi G, Boly M (2011) Propofol anesthesia and sleep: a high-density EEG study. Sleep 34:283-291. Medline

Nir Y, Staba RJ, Andrillon T, Vyazovskiy VV, Cirelli C, Fried I, Tononi G (2011) Regional slow waves and spindles in human sleep. Neuron 70: 153-169. CrossRef Medline

Nunez PL, Pilgreen KL (1991) The spline-Laplacian in clinical neurophysiology: a method to improve EEG spatial resolution. J Clin Neurophysiol 8:397-413. CrossRef Medline

Purdon PL, Pierce ET, Mukamel EA, Prerau MJ, Walsh JL, Wong KF, SalazarGomez AF, Harrell PG, Sampson AL, Cimenser A, Ching S, Kopell NJ,
Tavares-Stoeckel C, Habeeb K, Merhar R, Brown EN (2013) Electroencephalogram signatures of loss and recovery of consciousness from propofol. Proc Natl Acad Sci U S A 110:E1142-E1151. CrossRef Medline Roopun AK, Kramer MA, Carracedo LM, Kaiser M, Davies CH, Traub RD, Kopell NJ, Whittington MA (2008) Temporal interactions between cortical rhythms. Front Neurosci 2:145-154. CrossRef Medline

Smith AC, Shah SA, Hudson AE, Purpura KP, Victor JD, Brown EN, Schiff ND (2009) A Bayesian statistical analysis of behavioral facilitation associated with deep brain stimulation. J Neurosci Methods 183:267-276. CrossRef Medline

Steriade M, Nuñez A, Amzica F (1993) A novel slow ( $<1 \mathrm{~Hz}$ ) oscillation of neocortical neurons in vivo: depolarizing and hyperpolarizing components. J Neurosci 13:3252-3265. Medline

Steriade M, Amzica F, Contreras D (1994) Cortical and thalamic cellular correlates of electroencephalographic burst suppression. Electroencephalogr Clin Neurophysiol 90:1-16. CrossRef Medline

Supp GG, Siegel M, Hipp JF, Engel AK (2011) Cortical hypersynchrony predicts breakdown of sensory processing during loss of consciousness. Curr Biol 21:1988-1993. CrossRef Medline

Tort AB, Komorowski R, Eichenbaum H, Kopell N (2010) Measuring phase-amplitude coupling between neuronal oscillations of different frequencies. J Neurophysiol 104:1195-1210. CrossRef Medline

Vanhatalo S, Palva J, Holmes M, Miller J, Voipio J, Kaila K (2004) Infraslow oscillations modulate excitability and interictal epileptic activity in the human cortex during sleep. Proc Natl Acad Sci U S A 101:5053-5057. CrossRef Medline

Vanhaudenhuyse A, Demertzi A, Schabus M, Noirhomme Q, Bredart S, Boly M, Phillips C, Soddu A, Luxen A, Moonen G, Laureys S (2011) Two distinct neuronal networks mediate the awareness of environment and of self. J Cogn Neurosci 23:570-578. CrossRef Medline 